\title{
What is Air? A Standard Model for Combustion Simulations
}

\author{
L. D. Cloutman
}

\section{August 1, 2001}

\section{U.S. Department of Energy}

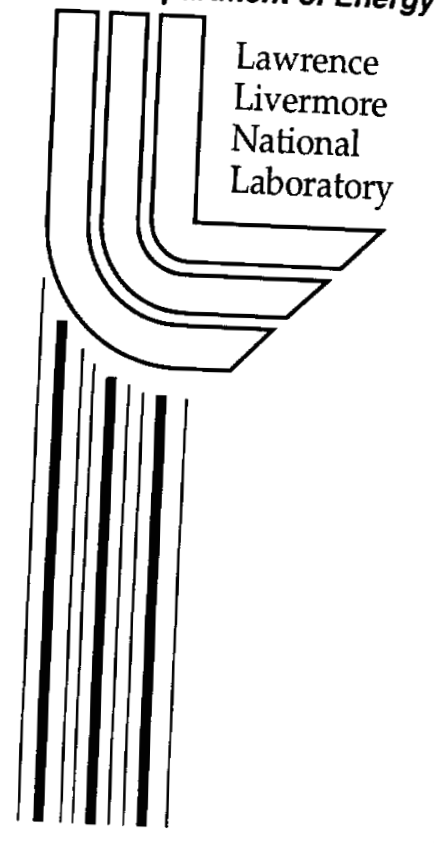




\section{DISCLAIMER}

This document was prepared as an account of work sponsored by an agency of the United States Government. Neither the United States Government nor the University of California nor any of their employees, makes any warranty, express or implied, or assumes any legal liability or responsibility for the accuracy, completeness, or usefulness of any information, apparatus, product, or process disclosed, or represents that its use would not infringe privately owned rights. Reference herein to any specific commercial product, process, or service by trade name, trademark, manufacturer, or otherwise, does not necessarily constitute or imply its endorsement, recommendation, or favoring by the United States Government or the University of California. The views and opinions of authors expressed herein do not necessarily state or reflect those of the United States Government or the University of California, and shall not be used for advertising or product endorsement purposes.

This work was performed under the auspices of the U. S. Department of Energy by the University of California, Lawrence Livermore National Laboratory under Contract No. W-7405-Eng-48.

This report has been reproduced directly from the best available copy.

Available electronically at http://www.doc.gov/bridge

Available for a processing fee to U.S. Department of Energy

And its contractors in paper from

U.S. Department of Energy

Office of Scientific and Technical Information

P.O. Box 62

Oak Ridge, TN 37831-0062

Telephone: (865) 576-8401

Facsimile: (865) 576-5728

E-mail: reports@adonis.osti.gov

Available for the sale to the public from

U.S. Department of Commerce

National Technical Information Service

5285 Port Royal Road

Springfield, VA 22161

Telephone: (800) 553-6847

Facsimile: (703) 605-6900

E-mail: orders@ntis.fedworld.gov

Online ordering: http://www.ntis.gov/ordering.htm

OR

Lawrence Livermore National Laboratory

Technical Information Department's Digital Library

http://www.llnl.gov/tid/Library.html 
Lawrence Livermore National Laboratory Report

UCRL-ID-

August 2001

\title{
WHAT IS AIR? \\ A STANDARD MODEL FOR COMBUSTION SIMULATIONS
}

\author{
Lawrence D. Cloutman
}

\begin{abstract}
Most combustion devices utilize air as the oxidizer. Thus, reactive flow simulations of these devices require the specification of the composition of air as part of the physicochemical input. A mixture of only oxygen and nitrogen often is used, although in reality air is a more complex mixture of somewhat variable composition. We summarize some useful parameters describing a standard model of dry air. Then we consider modifications to include water vapor for creating the desired level of humidity. The "minor" constituents of air, especially argon and water vapor, can affect the composition by as much as about 5 percent in the mole fractions.
\end{abstract}




\section{Introduction}

What is air? At first glance, this is a trivial if not silly question, one whose answer is well known. Indeed, air is well studied and reliable data on its properties are readily available. However, there is an aspect of this question that is less obvious: If one wants to do numerical simulations of reactive flows involving air to some specified level of accuracy, how much detail about the composition and physical properties of air must be included? That question is neither trivial nor silly.

One would think that simulating a combustion experiment in which air is the oxidizer would be a simple and straightforward task. After all, air is mostly molecular nitrogen and oxygen, and in many studies this is all that is assumed. However, we are entering an era in which we can expect computational fluid dynamics (CFD) simulations to provide accuracies at the few percent level for many flow variables, and this requires eliminating as many sources of error at the one percent level and above as is practical. At that level of detail, air is not such a simple substance.

For example, consider the relatively simple problem of determining flame speeds for one-dimensional laminar flames for various fuels under various conditions of stoichiometry, initial temperature, and pressure. Let us assume for the sake of argument that we would like the simulations to be accurate to $1 \mathrm{~cm} / \mathrm{s}$, which for most hydrocarbon fuels is a relative error on the order of 1-3 percent of the peak flame speed. This means that all physical data must be accurate to about a percent, if not better. This includes the thermal and caloric equations of state, transport coefficients, chemical reaction rates, and composition of the gases. We are not even going to consider here the questions of the adequacy of the governing equations or the accuracy of the numerical methods used to solve them. For most practical situations, the equations of state are quite accurately known, although the compressibility of air deviates from unity by about one percent near top dead center in a diesel engine. Transport coefficients and reaction rates are less well known, and (unfortunately) the "tuning" of reaction rates sometimes is used to compensate for inadequate knowledge of other quantities in an effort to force a fit to experimental flame speed data. However, one part of the physical input that is known sufficiently accurately is the composition of dry air, and there no reason to avoid using that knowledge.

There are several issues that must be addressed when modeling air in a reactive flow simulation. First, air is a complex mixture of somewhat variable composition. In most combustion applications, the thermal equation of state is well approximated by the ideal gas law. However, the caloric equation of state must include the temperature dependence of the specific heats. This has been standard practice for many years and is well understood. However, less attention has been paid to inclusion of less abundant species that may 
nevertheless have an influence at the few percent level: argon is present at the one percent level, and water may be present up to a few percent in the ambient air in a laboratory, depending on the relative humidity. These species have three effects: they have their own individual species equations of state, they act as a diluent of the oxygen, and they may show different chemical effects than other species. This latter effect can appear, for example, in the form of non-unity third body efficiencies or as an active chemical species, such as the importance of water in carbon monoxide combustion $[1,2]$. Second, the air pressure affects reactive flows, influencing for example, laminar flame speeds and flame thicknesses. It also affects the molecular transport coefficients and thereby numerous dimensionless parameters including the Reynolds number.

The point of this note is that in modern combustion simulations, air composition should be more detailed than a simple nitrogen-oxygen mixture. Section 2 describes a set of parameters for a standard model of dry air. Section 3 discusses issues surrounding the inclusion of water vapor. Conclusions are presented in Section 4.

\section{A Standard Atmosphere}

Not only is air a mixture of many different gases, its composition is somewhat variable. Therefore, for our calculations, we adopt the parameters for dry air given in reference [3] on page 14-11. We include the four most abundant species plus water vapor. For dry air, the standard mole fractions are $X_{\mathrm{N}_{2}}=0.780840$ for nitrogen, $X_{\mathrm{O}_{2}}=0.209476$ for oxygen, $X_{\mathrm{Ar}}=0.009340$ for argon, and $X_{\mathrm{CO}_{2}}=0.000344$ carbon dioxide. Various amounts of water vapor will generally be present in actual experiments.

There are several trace species also present: neon $\left(X_{\mathrm{Ne}}=1.818 \times 10^{-5}\right)$, helium $\left(X_{\mathrm{He}}=5.24 \times 10^{-6}\right)$, krypton $\left(X_{\mathrm{Kr}}=1.14 \times 10^{-6}\right)$, xenon $\left(X_{\mathrm{Xe}}=8.7 \times 10^{-8}\right)$, methane $\left(X_{\mathrm{CH}_{4}}=2.0 \times 10^{-6}\right)$, hydrogen $\left(X_{\mathrm{H}_{2}}=5.0 \times 10^{-7}\right)$. We shall neglect these in most cases, although they can be included in a CFD simulation if desired.

Multicomponent flow programs require composition input in one of several forms, the most common of which are mole fractions and total density, mass fractions and total density, and species densities. The combustion literature generally uses mole fractions. However, it is useful to be able to convert mole fractions to mass fractions. We define the mass fraction of species $\alpha$ as $Y_{\alpha}=\rho_{\alpha} / \rho$, the ratio of the species density $\rho_{\alpha}$ to the total density $\rho=\Sigma_{\alpha} \rho_{\alpha}$. The molar concentration of species $\alpha$ is $c_{\alpha}=\rho_{\alpha} / M_{\alpha}$, where $M_{\alpha}$ is the molecular weight of species $\alpha$. We define the mean molecular weight of a mixture, $M$, such that the total molar concentration is $\rho / M=\sum_{\alpha} c_{\alpha}$. Then it is easy to show that

$$
M=\left(\sum_{\alpha} Y_{\alpha} / M_{\alpha}\right)^{-1}=\sum_{\alpha} M_{\alpha} X_{\alpha},
$$


where $X_{\alpha}=Y_{\alpha} M / M_{\alpha}$ is the mole fraction of species $\alpha$. So, given either the molar or mass fractions, we can calculate $M$ and then convert to the other quantity.

Table 1 gives molecular weights and other data for a selection of molecules commonly encountered in combustion research. The molecular weights for molecules were computed from the molecular weights of atoms, taken from reference [3], so chemical changes will maintain mass conservation to within computer roundoff. A more complete list of species data is given in reference [4].

Table 2 presents the listing of a very simple code, X2Y, that makes the conversion from mole fraction to mass fraction. Input numbers are inserted directly into the code, which is then compiled and executed. The table also gives the output (mass fractions and mean molecular weight $M$ ) for the standard dry air composition described in the first paragraph.

There are several other parameters that sometimes are useful. Consider the sea level values for the standard atmosphere given on page 14-13 of reference [3]. The density is $1.2250 \times 10^{-3} \mathrm{~g} / \mathrm{cm}^{3}$, the standard gravitational acceleration is $980.66 \mathrm{~cm} / \mathrm{s}^{2}$, the pressure is $1.01325 \mathrm{bar}=760 \mathrm{~mm} \mathrm{Hg}$, the mean molecular weight is 28.964 , and the temperature is $15 \mathrm{C}=288.15 \mathrm{~K}$. Transport coefficients are kinematic viscosity $=1.4607 \times 10^{-5} \mathrm{~m}^{2} / \mathrm{s}$, coefficient of viscosity $=1.7894 \times 10^{-5} \mathrm{~kg} /(\mathrm{m} \mathrm{s})$, and thermal conductivity $=2.5326 \times 10^{-2}$ $\mathrm{J} /(\mathrm{m} \mathrm{s} \mathrm{K})$. The speed of sound is $340.29 \mathrm{~m} / \mathrm{s}$, the mean free path is $6.6332 \times 10^{-6} \mathrm{~cm}$, and the collision frequency is $6.9189 \times 10^{9} \mathrm{~s}^{-1}$. The number density is $2.5470 \times 10^{19} \mathrm{~cm}^{-3}$. The pressure scale height is $8434.5 \mathrm{~m}$.

There are several adjustments that can be made to the standard atmosphere, depending on the location of the laboratory making the measurements. Lide [3], page 14-7, gives a fitting formula for adjusting the local acceleration of gravity:

$$
g\left(\mathrm{~m} / \mathrm{s}^{2}\right)=9.780356\left(1+0.0052885 \sin ^{2} \phi-0.0000059 \sin ^{2} 2 \phi\right)-0.003086 H,
$$

where $\phi$ is the latitude in degrees and $H$ is the altitude in kilometers. The standard temperature and pressure may be adjusted for altitude by (page 14-12)

$$
T=288.15-0.006500 H
$$

and

$$
P=1.01325(288.15 / T)^{-5.255877},
$$

where $H$ is in $\mathrm{m}$ and $P$ is in bars. These approximations are valid for altitudes in the range $-1524<H<11000 \mathrm{~m}$. 
Table 1. Species Gas Properties

\begin{tabular}{rrrrrrrr}
\hline \multicolumn{1}{c}{$M_{\alpha}$} & $H_{\alpha}$ & $\sigma_{\alpha}$ & $\epsilon / k$ & $A_{e q}$ & $b_{e q}$ & $E_{e q}$ \\
\hline $\mathrm{CH}_{4}$ & 16.04296 & $-6.69110+11$ & 3.746 & 141.40 & $1.51456-06$ & 0.0 & -21.9712 \\
$\mathrm{O}_{2}$ & 31.99880 & 0.0 & 3.458 & 107.40 & 1.0 & 0.0 & 0.0 \\
$\mathrm{~N}_{2}$ & 28.01340 & 0.0 & 3.621 & 97.53 & 1.0 & 0.0 & 0.0 \\
$\mathrm{CO}_{2}$ & 44.01000 & $-3.93150+12$ & 3.763 & 244.00 & $1.12780+01$ & -0.286036 & -93.7359 \\
$\mathrm{H}_{2} \mathrm{O}$ & 18.01528 & $-2.38919+12$ & 2.641 & 809.10 & $2.03999-02$ & -0.356445 & -58.6397 \\
$\mathrm{H}$ & 1.00794 & $2.16035+12$ & 2.050 & 145.00 & $1.61801+01$ & 0.514866 & 52.1438 \\
$\mathrm{H}_{2}$ & 2.01588 & 0.0 & 2.920 & 38.00 & 1.0 & 0.0 & 0.0 \\
$\mathrm{O}$ & 15.99940 & $2.46790+12$ & 2.750 & 80.00 & $2.64100+02$ & 0.286036 & 59.8602 \\
$\mathrm{~N}$ & 14.00670 & $4.70784+12$ & 3.298 & 71.40 & $1.27475+02$ & 0.369647 & 113.213 \\
$\mathrm{OH}$ & 17.00734 & $3.88652+11$ & 2.750 & 80.00 & $2.46399+01$ & -0.180423 & 9.48250 \\
$\mathrm{CO}$ & 28.01060 & $-1.13805+12$ & 3.650 & 98.10 & $4.27854+07$ & -0.875711 & -24.9755 \\
$\mathrm{NO}$ & 30.00610 & $8.97719+11$ & 3.621 & 97.53 & $4.60300+00$ & 0.0 & 21.6200 \\
$\mathrm{Ar}$ & 39.94800 & 0.0 & 3.330 & 136.50 & 1.0 & 0.0 & 0.0 \\
\hline $\mathrm{He}$ & 4.00206 & 0.0 & 2.576 & 10.20 & 1.0 & 0.0 & 0.0 \\
$\mathrm{Ne}$ & 20.1797 & 0.0 & 2.749 & 35.60 & 1.0 & 0.0 & 0.0 \\
$\mathrm{Kr}$ & 83.80 & 0.0 & 3.679 & 176.00 & 1.0 & 0.0 & 0.0 \\
$\mathrm{Xe}$ & 131.29 & 0.0 & 3.937 & 229.80 & 1.0 & 0.0 & 0.0 \\
\hline
\end{tabular}

The heats of formation $H_{\alpha}$ are in units of ergs $/ \mathrm{mol}$, and $E_{\text {eq }}$ is in $\mathrm{kcal} / \mathrm{mol}(R=1.9872 \times$ $\left.10^{-3}\right)$. The Lennard-Jones parameters $\sigma_{\alpha}$ and $\epsilon / k$ are in units of $\AA$ and $\mathrm{K}$, respectively. The species equilibrium constants are $K_{P}=A_{e q} T^{b_{e q}} \exp \left(-E_{e q} / R T\right)$ atm.

\section{What About Water Vapor?}

The most changeable composition variable is the water vapor mole fraction. It can vary from zero up to a mole fraction of about 0.04 under standard conditions. If one is interested in attaining simulation accuracy of one percent, then the amount of water present in the ambient air must be specified. The commonly measured quantities are the relative humidity and the temperature. The vapor pressure of water can be computed from the temperature, which can be combined with the relative humidity to give the partial pressure of water, which then provides the mole fraction by use of the ideal gas equation of state.

The vapor pressure of water is a rapidly increasing function of temperature. Table 3 gives the vapor pressure as a function of temperature. The critical conditions for water are $P_{c}=22.064 \mathrm{MPa}=220.64 \mathrm{bars}, \rho_{c}=0.322 \mathrm{~g} / \mathrm{cm}^{3}$, and $T_{c}=647.14 \mathrm{~K}$. One must be careful that the air-water mixture does not have a partial pressure of water above the vapor pressure. This should not be an issue in combustion products since they are usually well above the critical temperature, but it is a potential hazard in initializing the air composition for the reactants. The next most likely species to exhibit condensation is carbon dioxide, 
but we will be unlikely to encounter problems under typical combustion conditions since the critical temperature is only $304 \mathrm{~K}$.

Table 3. Vapor Pressure of Water

\begin{tabular}{rr}
\hline$T(\mathrm{C})$ & $P_{\text {vapor }}(\mathrm{kPa})$ \\
\hline 0 & 0.6113 \\
10 & 1.2281 \\
20 & 2.3388 \\
30 & 4.2455 \\
40 & 7.3814 \\
50 & 12.344 \\
60 & 19.932 \\
70 & 31.176 \\
80 & 47.373 \\
90 & 70.117 \\
100 & 101.325 \\
\hline
\end{tabular}

\section{Conclusions}

Typically, experimental papers indicate (or merely imply) that the conditions are ambient laboratory conditions, if that. This is inadequate for highly accurate reactive-flow CFD simulations. At the very least, we should have the temperature, barometric pressure, and the relative humidity specified. The location of the experiment (latitude and especially altitude) also might be useful in some cases. The information presented here will allow then the estimation of reliable composition parameters for the air, which will improve the accuracy of the simulations. Also, we recommend against replacing minor components of air, such as argon and water, by surrogates such as nitrogen or carbon dioxide since the equations of state and chemical activities are different and may lead to effects at the level of a few percent in the simulations.

There is the issue of added computational expense. However, we note that in all but the most primitive global kinetics mechanisms, all the required species with the possible exception of argon are already being carried in the calculations. It is my experience that carrying this one additional species incurs minor additional computational expense, typically at the one percent level.

Similar considerations apply to the composition of fuels, especially natural gas. Natural gas is even more variable in composition than air and may contain over 10 percent of gases other than methane. Some of these are chemically rather inert (such as $\mathrm{N}_{2}$ ), while 
others are chemically active (such as ethane and other light alkanes). In many experiments, technical grades of bottled gases are used as the fuel, and these can contain over one percent contaminants that perhaps cannot be ignored in numerical simulations of high accuracy.

\section{Acknowledgments}

This work was performed under the auspices of the U.S. Department of Energy by University of California Lawrence Livermore National Laboratory under contract number W-7405-ENG48.

\section{References}

[1] B. Rogg and F. A. Williams, "Structures of wet CO flames with full and reduced kinetic mechanisms," 22nd Symposium (International) on Combustion (Combustion Institute, Pittsburgh, 1968), 1441.

[2] R. A. Yetter, F. L. Dryer, and H. Rabitz, "Flow reactor studies of carbon monoxide/hydrogen/oxygen kinetics," Combust. Sci. and Tech. 79, 129 (1991).

[3] D. R. Lide, Ed., CRC Handbook of Chemistry and Physics, 73rd Edition (CRC Press, Boca Raton, 1992).

[4] Cloutman, L. D., "A Selected Library of Transport Coefficients for Combustion and Plasma Physics Applications," Lawrence Livermore National Laboratory report UCRLID-139893, 2000. 
Table 2. X2Y.f Listing

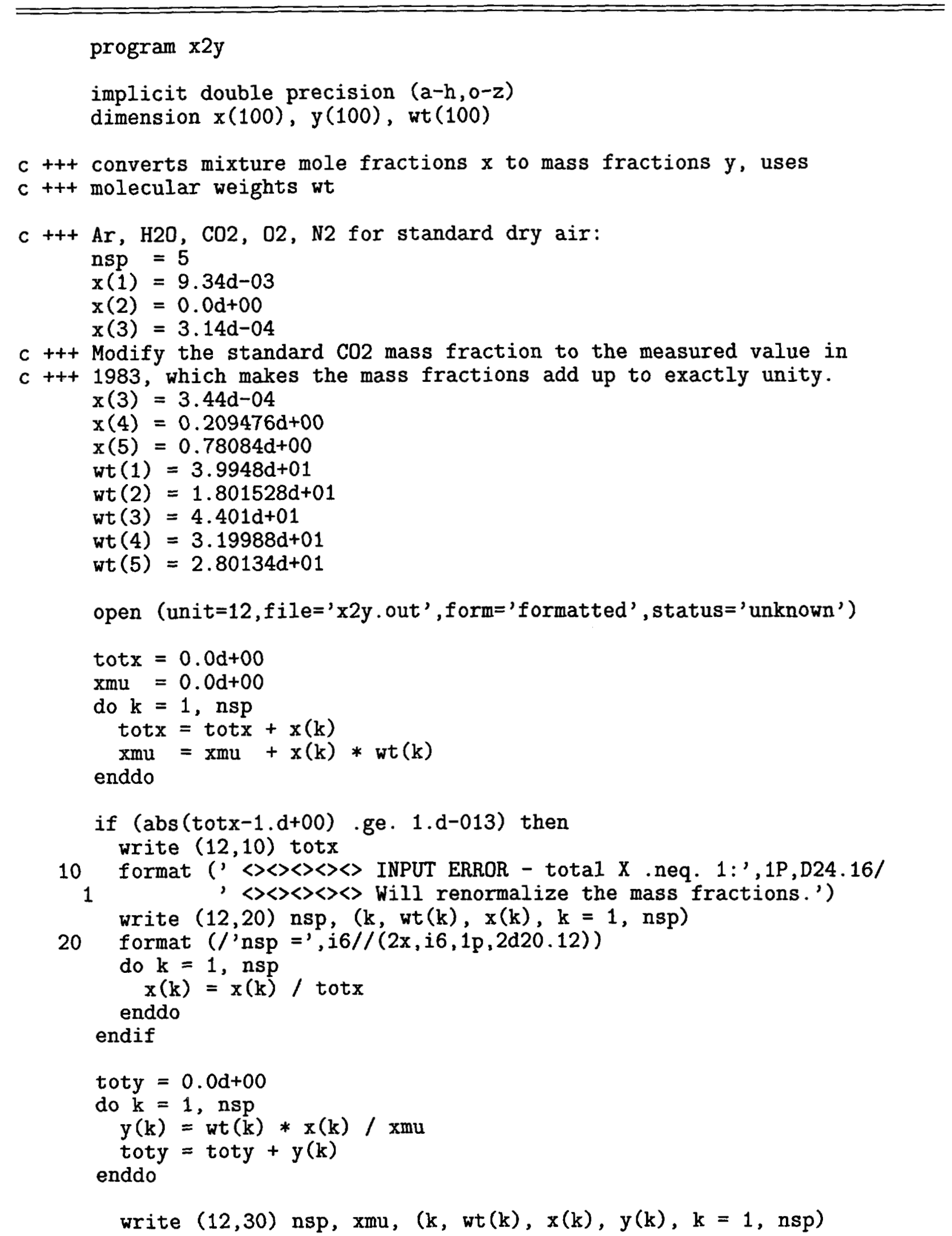




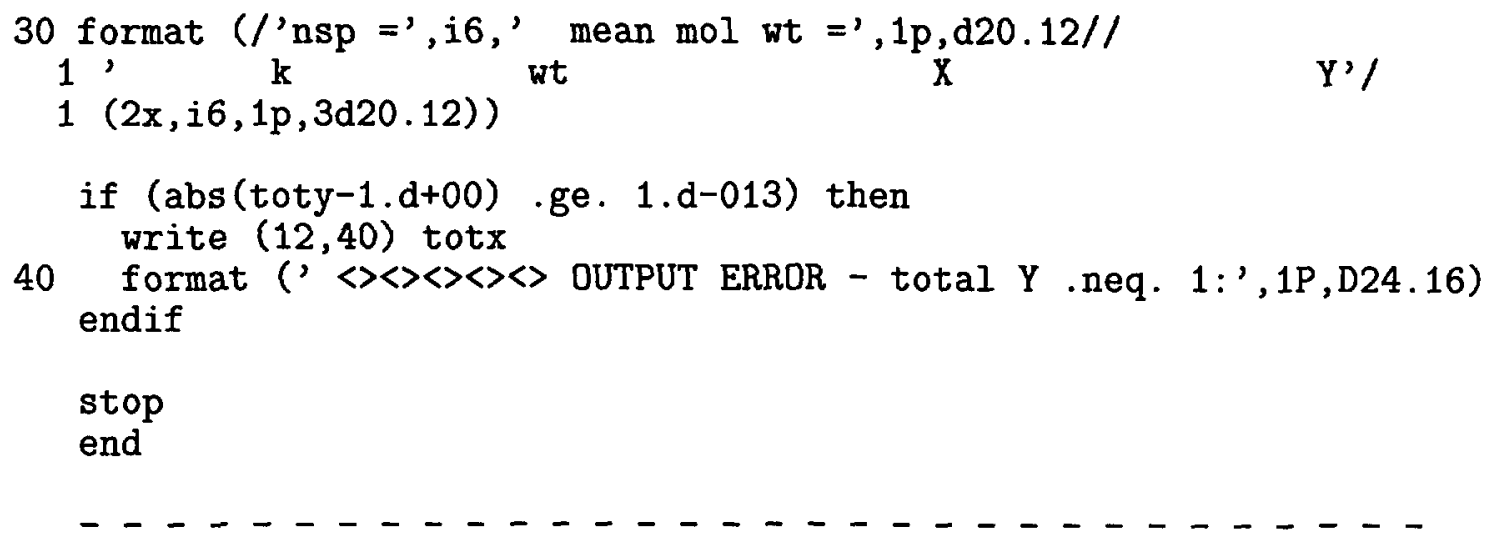

OUTOUT :

$\mathrm{nsp}=\quad 5$ mean mol wt $=2.896521764480 \mathrm{E}+01$
k
wt
$\mathrm{X}$
Y
$13.994800000000 \mathrm{E}+01 \quad 9.340000000000 \mathrm{E}-03$
$1.801528000000 \mathrm{E}+01$
$0.000000000000 \mathrm{E}+00$
$1.288146095001 \mathrm{E}-02$
$4.401000000000 \mathrm{E}+01$
$3.440000000000 E-04$
$0.000000000000 \mathrm{E}+00$
$\begin{array}{ll}3 & 4.401000000000 \mathrm{E}+01 \\ 4 & 3.199880000000 \mathrm{E}+01\end{array}$
$2.094760000000 \mathrm{E}-01$
$5.226765490132 \mathrm{E}-04$
$52.801340000000 \mathrm{E}+01$
$7.808400000000 \mathrm{E}-01$
$2.314148200438 \mathrm{E}-01$
7.551810424572E-01 